International Journal of Computer Networks \& Communications (IJCNC) Vol.3, No.3, May 2011

\title{
BER ANalysis of Multi-Code Multi-CarRier CDMA SYSTEMS IN MULTIPATH FADING CHANNEL
}

\author{
Md. Sadek Ali ${ }^{1}$, Md. Shariful Islam ${ }^{1}$, Md. Alamgir Hossain ${ }^{1}$, Md. Khalid \\ Hossain Jewel ${ }^{2}$ \\ ${ }^{1}$ Dept. of Information \& Communication Engineering \\ ${ }^{2}$ Dept. of Applied Physics, Electronics \& Communication Engineering \\ Islamic University, Kushtia 7003, Bangladesh. \\ E-mail : \{ sadek_ice, afmsi76, alamgir_ict, khalidjewel\}@yahoo.com
}

\begin{abstract}
This paper proposes a Multi-Code Multi-Carrier Code Division Multiple Access (CDMA) scheme for next generation wireless communication systems. This system retains the advantages of Multi-Carrier CDMA in combating multipath and rejecting interference, and provides variable and adaptive data rates through the use of Multi-Code scheme. The rate adaptation algorithm proposed computes the user data rate as a function of the instantaneous channel condition and application dependent data rates. Exploiting the channel information improves the effective data rate and overall capacity of the system. The performance improvement of the proposed system to the Multi-Code CDMA system is shown through simulations. Walsh-Hadamard, Gold and Kasami codes are explored as possible choices for the multiple codes in the system.
\end{abstract}

\section{KEYWORDS}

AWGN, MC-CDMA, OFDM.

\section{INTRODUCTION}

Future wireless systems like 4th generation (4G) cellular systems aim to integrate a variety of services such as voice, data, image, and video. These services have different requirements on the bandwidth and the rate of transmission on a wireless platform. To this end, future generation systems will have to handle a variety of bit rates. Moreover, wireless channels are characterized by multipath propagation, motion induced temporal variations, and multiple access interference. In recent years, there has been a tremendous amount of research on spread spectrum techniques, which have been proved to be attractive choices to combat fading effects of the channel and Multi-Code systems which promise variable data rates [1]. In a CDMA based system that can provide a smooth integration path to Personal Computer System (PCS), either from a digital cellular system or from a wideband CDMA system, to serve both synchronous and asynchronous applications, has been proposed. This approach, dubbed Multi-Code CDMA realizes a unified digital bandwidth-on-demand platform by allocating multiple codes, and hence increased capacity to users. When the user needs $M$ times the basic source rate, the incoming data stream is converted into $\mathrm{M}$ parallel sub-streams and each of the sub streams is spread with a different spreading sequence and added together before transmission. The data rate is proportional to the number of codes assigned to the user.

A variation of multi-code scheme, which supports variable data rates by variation of the set of code sequences assigned to the each user, has been proposed [2]. The users transmit their data by choosing one sequence from their code set and transmitting over the common channel. 
Thereby, with $\mathrm{M}$ codes, a user can transmit $\log _{2} \mathrm{M}$ bits per sequence period. The data rate is increased by increasing the number of codes used for the transmission.

Extensive research on multi-rate transmission on single-carrier CDMA systems in AWGN channels has been carried out [3][4]. There have been a few studies on multi-rate transmission in Multi-carrier Direct Sequence CDMA systems [5][6]. A new multi-carrier DS-CDMA with multi-code in which input data bits are first coded at a low rate $(1 / R)$ and every resulting $R$ coded binary bits are then multiplexed with a set of multi-codes to produce code division multiplexing super-bits. After serial-to-parallel conversion, these super-bits are spread using $\mathrm{M}$ orthogonal carriers.

Multi-rate transmission for single-carrier CDMA systems in AWGN channels has been previously considered in the literature, e.g. [7]. It is also an important part on third generation cellular standards, namely CDMA2000 1xEV-DO [8] and 1xEV-DV [9], known sometimes as HDR [10]. HDR supports diverse data rates using many codes with different spreading factors. Techniques such as Multi-Code CDMA system [11] - [14] and Multi-Carrier CDMA system [15] - [17] have been suggested in recent years. Multi-Carrier CDMA is a technique to improve the efficiency of frequency using several subbands in the particular frequency band and spreading each subcarrier over the total bandwidth, a combination of Multi-Carrier modulation and DS/SS-CDMA technique. In the Multi-Carrier CDMA system [18], the high rate data stream is divided into several low rate data substreams, each substream modulates a different subcarrier and is spread over the whole bandwidth before transmitting the data stream. Similarly, Multi-Code CDMA [19] is a technique for high rate service and multi rate service using orthogonal code sequence. In the Multi-Code CDMA, the high rate data stream is divided into several low rate data substream, and then each substream is multiplied with an orthogonal code set to discriminate each substream and minimize Inter-Substream Interference (ISSI) before transmitting data.

Multi-Code CDMA and Multi-Carrier CDMA have attracted a lot of attention from researchers due to their perceived high data rate transmission capability. InMulti-Code CDMA, researchers have investigated the systems performance in different fading channel [11] - [13] and suggested many schemes to improve the performance [15]. In [19], input data streams are first split into several substreams in parallel and then orthogonal codes are multiplied for each substream. When signals from transmitter arrive at the receiver, the signals are distorted by some noise in the channel and the interference between signals due to propagation delay. In [14], it was shown that using interference cancellation in Multi-Code CDMA reduces the interference at the receiver. Codes suitable for minimizing interference between substreams in Multi-Code CDMA have been analyzed in [15]. In [20], a new architecture was proposed to reduce system complexity at the receiver when multi-codes are used.

In Multi-Carrier CDMA, input data streams are first split into several substreams in parallel, like in Multi-Code CDMA and then modulate several subcarriers with each substream before transmitting the signals. Similarly with Multi-Code CDMA, Multi-Carrier CDMA is analyzed with different fading channel in [16] [17]. In [21], researchers have suggested schemes to improve the system performance. Especially, diversity techniques [22] [23] are applied for the both systems to improve the system performance in multipath propagation environment. In [24], Parallel interference cancellation is applied to the Multi-Carrier CDMA. While synchronization algorithm and coded systems are evaluated in [25]. As multiple services with different bit rate in a system are currently receiving more attention, new multi-rate CDMA systems based on variable number of spreading codes or multiple multi-code sets have been suggested in [26][27][28]. Especially, [27] analyzed the performance of Multi-Carrier DS/CDMA system with two multi rate schemes: Multi-Code (MC) scheme and Multiple Processing Gain (MPG) scheme and compared two schemes in Rayleigh fading channel. It is shown in [27] that high rate service has smaller BER than low rate service in both schemes. In [28], Multi-Code MultiCarrier CDMA system was evaluated and compared with both single code multi-carrier CDMA 
system and multi-code CDMA system with single carrier in a frequency selective fading channel.

The study of multi-rate transmission for Multi carrier-Direct sequence CDMA systems are based on the concepts of multi-code access and variable-spreading gain code access [6]. In the multi-code scheme, the data stream of a user with rate $\mathrm{M}$ is first multiplexed into $\mathrm{M}$ different streams with basic data rate and each is treated as an individual user with individual spreading codes. Each stream is then serial-to-parallel converted into P parallel sub-streams and then the sub-streams from the same effective user are spread by the same spreading codes with a constant factor. All the corresponding parallel spread signals from other effective users are combined and transmitted by $\mathrm{P}$ orthogonal sub-carriers respectively.

The rest of the paper is organized as follows. In section two shows the detailed system model. Section three describes the proposed channel model. Simulation results are described in section four. Finally, section five concludes the paper.

\section{SySTEM MODEL}

\subsection{Multi-Code CDMA system}

A novel multi-code system has been proposed in to support variable data rates [2]. In this scheme, each user has a set of $M$ codes called the sequence set. The system is an M-ary modulation where a code sequence represents a sequence of $\log _{2} \mathrm{M}$ bits. The size of the sequence set depends on the required data rate. In the normal case, the set size is 2 , i.e., there are two sequences in the set, one to represent a ' 0 ' and one to represent a ' 1 '. When the data rate is to be made $\mathrm{L}$ times the standard data rate, the sequence set is made of size $2^{\mathrm{L}}$ and each sequence of $\mathrm{L}$ bits is mapped to one of the $2^{\mathrm{L}}$ code sequences.

Consider a system with $K$ users $(0 \leq k<K)$. Each user is assigned a sequence set

$$
F^{(k)}=\left\{S_{k}[m](n) \mid 1 \leq m \leq M\right\}
$$

of $\mathrm{M}$ sequences of length $\mathrm{N}$ with constant envelope. With these, $\mathrm{M}$-ary data symbols $b^{(k)}$ are transmitted at rate $1 / T$. The sequence set of each user is implemented as a chip wise product of a user specific sequence $U_{k}(n)$ and a set of information sequences $G[m](n), 1 \leq m \leq M$.

$$
F^{(k)}=\left\{S_{k}[m](n)=G[m](n) \cdot U_{k}(n) \mid 1 \leq m \leq M\right\}
$$

The sequences are modulated with the carrier signal $h(t)$. For simplicity, we assume

$$
h(t)=\frac{1}{\sqrt{T c}} \operatorname{rect}\left(\frac{t}{T c}-\frac{1}{2}\right) \quad \text {, where } \quad T c=T / N
$$

The symbol $b^{(k)}$ is mapped onto

$$
s_{k}\left[b^{(k)}\right](t)=\sum_{n=0}^{N-1} S_{k}\left[b^{(k)}\right](n) h(t-n T c)
$$

User $k$ transmits symbol $b^{(k)}$ at time $t=l T$. The signal of user $k$ then is

$$
s^{(k)}(t)=\sum_{l} S_{k}\left[b_{l}^{(k)}\right](t-l T)
$$

before modulation and

$$
m^{(k)}(t)=\operatorname{Re}\left(s^{(k)}(t) e^{j \sigma t}\right)
$$


after modulation. A block diagram of the Multi-Code CDMA system is shown in fig.1.

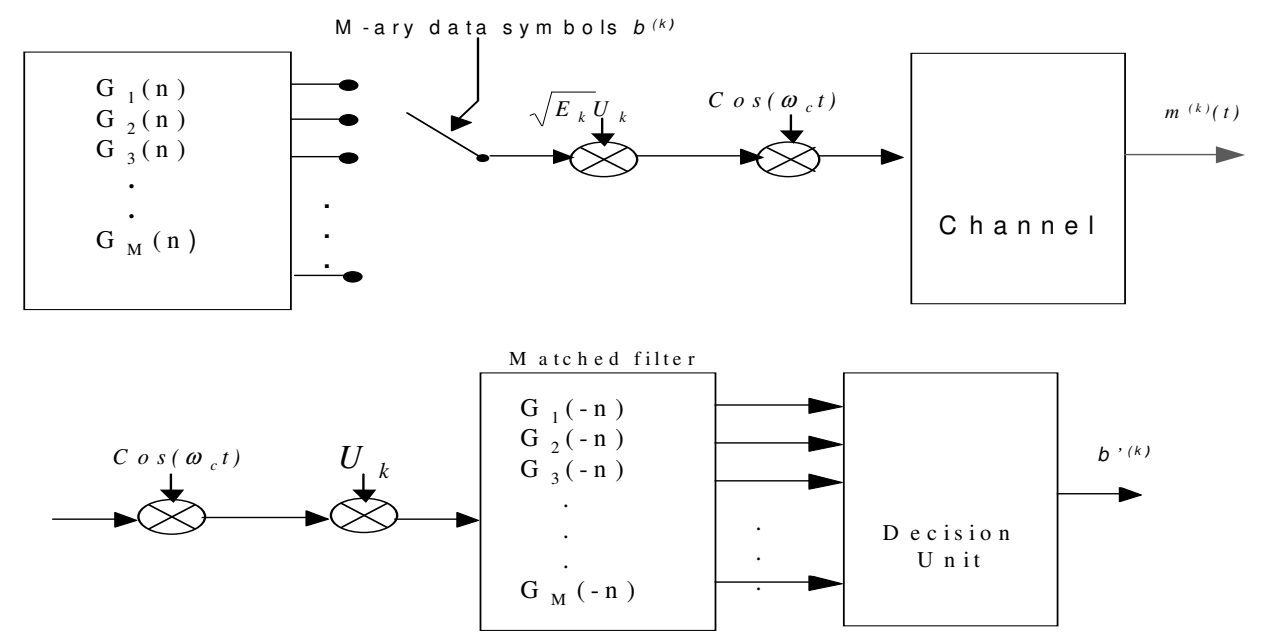

Figure 1. Transmitter and Receiver of Multi-Code CDMA System

As explained above, depending on the required data rate, each user has a set of $\mathrm{M}$ code sequences, where $M$ is the ratio of the base data rate and required data rate. The base rate is achieved with set of just two sequences. The M-ary symbol to be transmitted selects one of the code sequences of length $\mathrm{N}$, which is then multiplied chip-wise with the user specific sequence. The user-specific sequence is a PN sequence of the same length $\mathrm{N}$ as the code sequences. At the receiver a filter bank is used to detect the transmitted symbol. The received code sequence is first multiplied chip-wise with user sequence and the resultant is correlated with each of the possible $\mathrm{M}$ code sequences. The sequence that gives maximum correlation is then mapped back into an M-ary symbol.

\subsection{Multi-Carrier CDMA system}

There are several equivalent ways of describing Multi-Carrier CDMA (MC-CDMA) system. MC-CDMA can be considered as a form of spread spectrum with spreading in the frequency domain as the code is fixed over time but varies with sub carrier frequency. Another way of describing MC-CDMA is: DS-CDMA followed by an Inverse Fast Fourier Transform (IFFT). MC-CDMA can also be considered as Orthogonal Frequency Division Multiplexing (OFDM) with an orthogonal matrix operation performed on the user bits. As each bit is transmitted simultaneously on many sub carriers, MC-CDMA is a form of frequency diversity. Each sub carrier has a constant phase offset that forms the code to separate users. Consider a MC-CDMA system with $\mathrm{K}$ users $(0 \leq k<K)$. The transmitted signal for user $\mathrm{k}$ is described by the following equation [5]:

$$
s_{k}(t)=\sqrt{E_{k}} \sum_{n=-\infty}^{\infty} \sum_{p=1}^{P} b_{k}[n] u_{T}(t-n T) c_{k, p}[n] \cos \left(\varpi_{p} t\right)
$$

where $E k$ represents the symbol energy for the $k^{\text {th }}$ user, $b_{k}[n]$ is the data bit of user $k$ at time $n$, $c_{k, p}$ is the spreading sequence chip for user $k$ on sub carrier $p$, and $\omega_{p}$ is the angular frequency of sub carrier $p . \quad T$ is the symbol interval and $u_{T}(t)$ is a rectangular pulse of duration $T$ used to isolate successive symbols. 


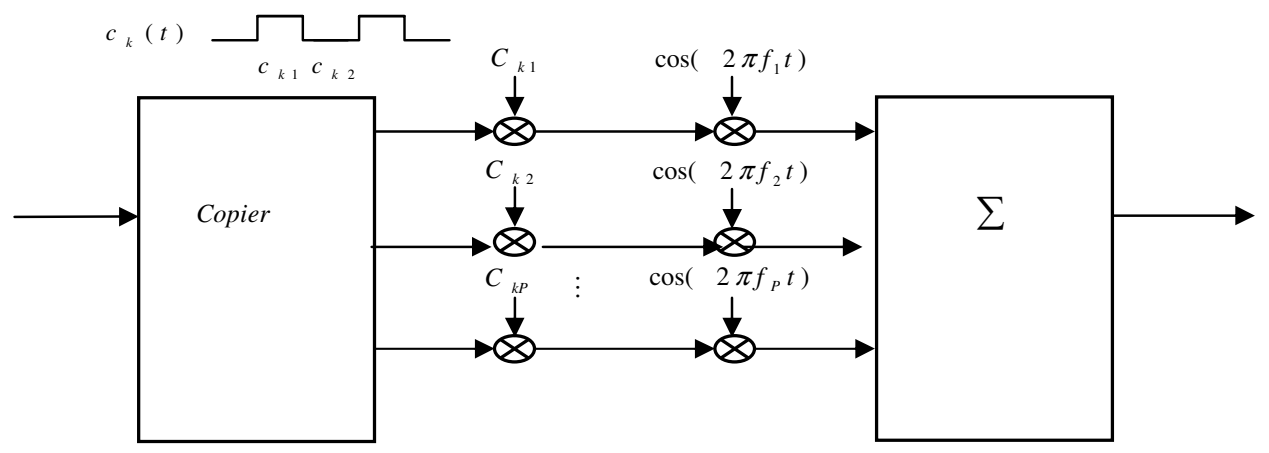

Figure 2. Transmitter of Multi-Carrier CDMA System

In Fig.2 the transmitter of a MC-CDMA system is depicted. Each chip is copied onto $P$ branches and multiplied by the corresponding chip of the user specific spreading code. Each branch then modulates a sub carrier and the modulated sub carriers are summed together and transmitted. There are several advantages of using MC-CDMA. One of them is multipath mitigation. There is constructive and destructive interference at the receiver due to multipath. Destructive interference causes deep nulls in the received signal power. For a narrowband transmission, if the frequency response null occurs at the signal frequency then the entire signal can be lost. However in wideband signals, dips in the spectrum result in a small loss of signal power. Also, if the transmission bandwidth is divided into many subcarriers, then spectral nulls are unlikely to occur at all of the subcarrier frequencies. Another advantage of MC-CDMA is simplified equalization in the frequency domain. However, equalization has not been considered in this paper.

\subsection{Multi-Code Multi-Carrier CDMA system}

To improve upon the performance of the Multi-Code CDMA system in a multipath fading channel, we have proposed a Multi-Code Multi-Carrier CDMA system and evaluated its performance. Fig.3 shows the transmitter of a Multi-Code MC-CDMA system.

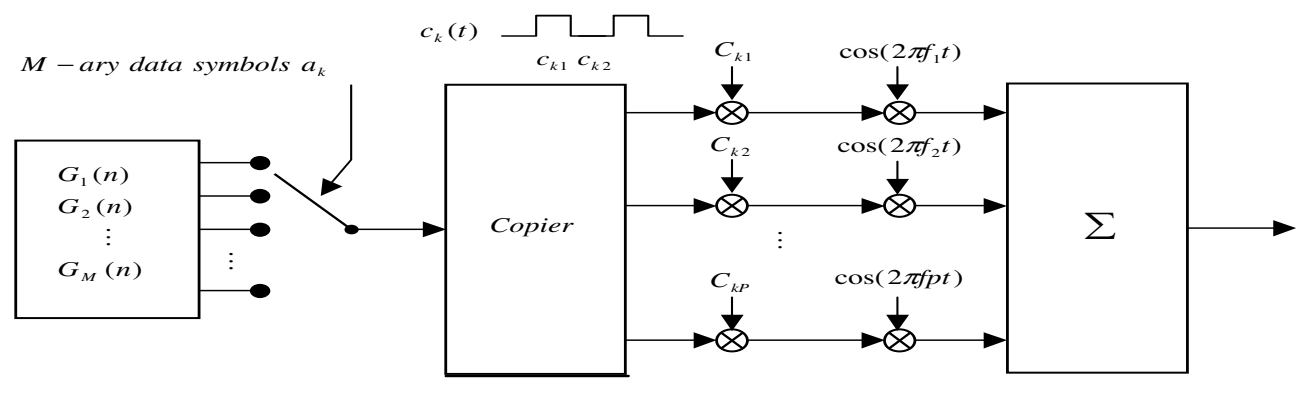

Figure 3. Transmitter of Multi-Code Multi-Carrier CDMA System

As in the Multi-Code CDMA transmitter, an M-ary symbol selects one of M code sequences for transmission. Each chip of the code sequence is copied onto $P$ branches. Each chip of the userspecific sequence is then multiplied with the corresponding branch i.e. the $p^{\text {th }}$ chip of the userspecific sequence is multiplied with the $p^{\text {th }}$ branch of the copier. Each of these branches then modulates one of the $P$ orthogonal subcarriers and the results are summed. This process can be implemented digitally using a size $P$ Inverse Fast Fourier Transform (IFFT) to replace the subcarrier multiplication and summation. At the receiver, a size $P$ FFT is applied to the input 
International Journal of Computer Networks \& Communications (IJCNC) Vol.3, No.3, May 2011

and the output of the FFT is then despread to generate each chip of the received code sequence. Detection then continues using the filter bank described for the Multi-code CDMA system. The use of this multicarrier scheme provides frequency diversity for multipath mitigation.

\section{Channel Model}

We assume multipath Rayleigh fading channel based on the Clarke and Gans model [29]. We used Smith's simulation method for implementation [30]. Fig. 4 shows simulated channel gain used in this work. Several multipath delay profiles are reported in [31]. Among them, we selected typical urban 6-ray model. Table-1 shows the power delay profile (PDP) of typical urban and bad urban case. Since our chip duration is $1 / 1.2288 \mathrm{Mcps}=0.8 \mu \mathrm{sec}$ and we didn't use the Rake receiver, we can't resolve first 3 components in that model. So, we combined those components to one component at $\tau=0 \mu \mathrm{sec}$, giving the power delay profile depicted in Fig.5. The rms delay spread $\sigma_{\tau}$ is $1.1 \mu \mathrm{s}$, and symbol duration Ts is $208 \mu \mathrm{s}$, which means flat fading.

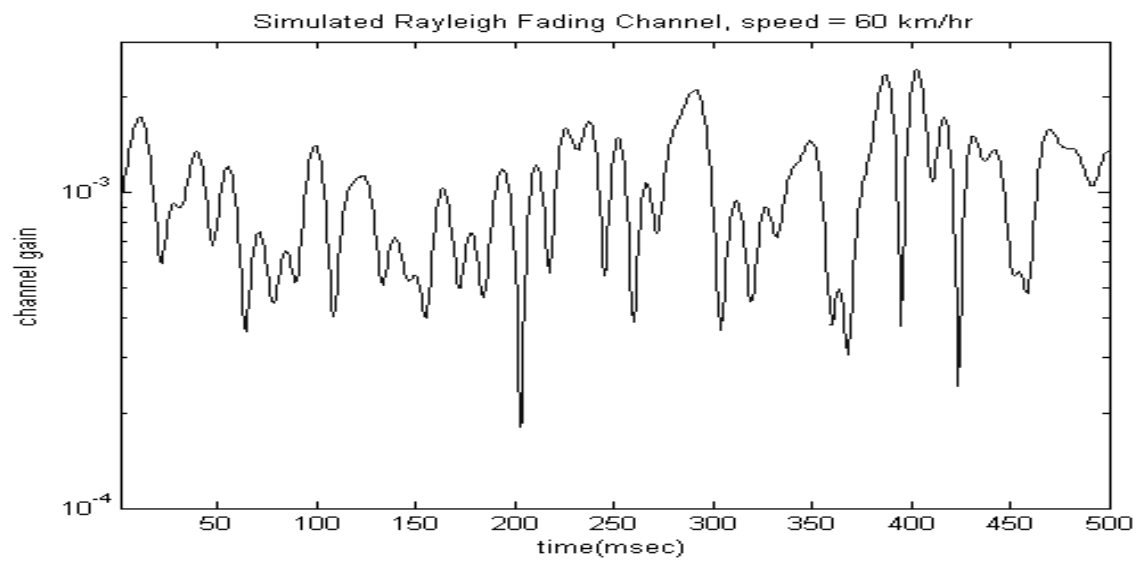

Figure 4. A typical Rayleigh fading channel gain

Table 1. Typical microcellular urban and bad urban 6-ray power delay profiles

\begin{tabular}{|c|c|c|c|}
\hline \multicolumn{2}{|c|}{ Typical Urban } & \multicolumn{2}{c|}{ Bad Urban } \\
\hline Delay, $\mu \mathrm{s}$ & $\begin{array}{c}\text { Fractional } \\
\text { Power }\end{array}$ & $\begin{array}{c}\text { Delay, } \\
\mu \mathrm{s}\end{array}$ & $\begin{array}{c}\text { Fractional } \\
\text { Power }\end{array}$ \\
\hline 0.0 & 0.189 & 0.0 & 0.164 \\
\hline 0.2 & 0.379 & 0.3 & 0.293 \\
\hline 0.5 & 0.239 & 1.0 & 0.147 \\
\hline 1.6 & 0.095 & 1.6 & 0.094 \\
\hline 2.3 & 0.061 & 5.0 & 0.185 \\
\hline 5.0 & 0.037 & 6.6 & 0.117 \\
\hline
\end{tabular}




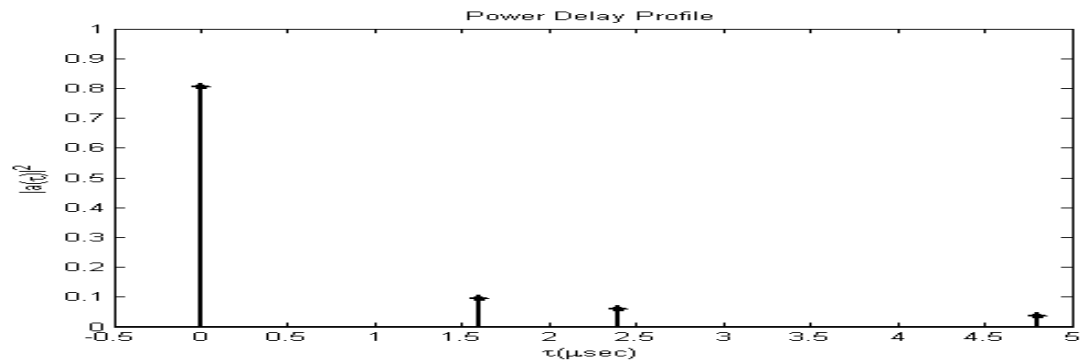

Figure 5. Power Delay Profile of Typical Urban 4-ray model

Current CDMA system controls transmission power frame by frame to solve the near-far problem. In this paper, we simplified the operation by assuming that every user transmits signal with same power. We didn't control power but has controlled the transmitting data rate to improve the spectral efficiency.

\section{Simulations}

We simulated MTC CDMA system and MTC-MC CDMA system with/without using rate adaptation in AWGN and in multipath fading channel. Table 2 shows the simulation parameters used. From the simulation parameters, speed of the vehicle and carrier frequency, the maximum Doppler shift is calculated to be $50 \mathrm{~Hz}$. In Fig. 6, it can be seen that the MTC CDMA system using Walsh codes for the multicode sequence sets outperforms the system using Gold and Kasami codes in AWGN channel. The analysis shows that the decoding decision variable at the receiver is related to the correlation properties of the code, which is used for the multicode sequence sets. Since Walsh code has the best orthogonality among the three codes used, the system using Walsh code performs the best.

Table 2. Simulation Parameters

\begin{tabular}{|c|c|}
\hline Parameter & Value \\
\hline Length of multicode sequence & 256 \\
\hline Chip rate for multicode sequence & $1.2288 \mathrm{Mcps}$ \\
\hline $\begin{array}{c}\text { Size of multicode sequence set } \mathrm{M} \\
\text { (M-ary symbol) }\end{array}$ & $2,4,8,16,32,128,256$ \\
\hline Speed of Vehicle & $60 \mathrm{Km} / \mathrm{h}$ \\
\hline Carrier frequency & $900 \mathrm{MH}_{\mathrm{z}}$ \\
\hline No. of subscriber & 16 \\
\hline
\end{tabular}

Fig.7 shows the BER performance versus No. of users for the MTC CDMA system using Walsh, Gold, and Kasami codes in AWGN channel. From Fig.7, Walsh code has the best BER performance. Hence, the system using Walsh code supports more users for the same BER as shown in Fig 7. Fig. 8 shows the BER performance versus SNR (dB) for the MTC CDMA system in multipath fading channel. Again, because of the synchronous transmissions, MTC CDMA using Walsh code shows the best performance. 
International Journal of Computer Networks \& Communications (IJCNC) Vol.3, No.3, May 2011

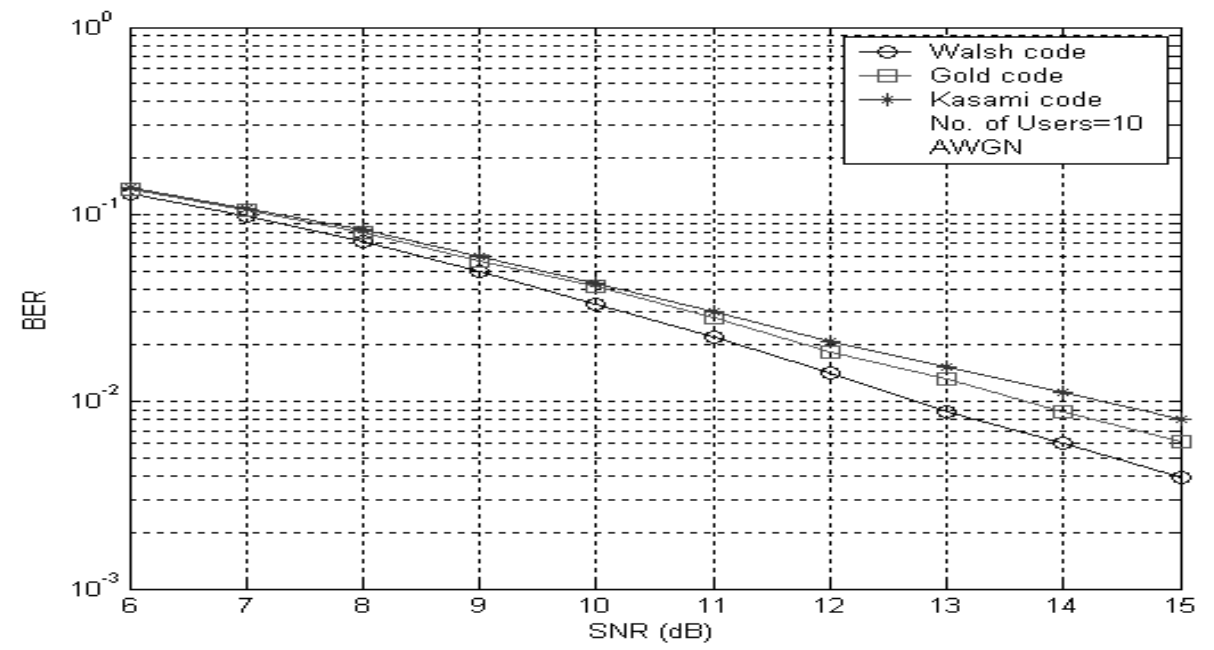

Figure 6. BER vs. SNR for MTC CDMA system using Walsh, Gold, and Kasami codes in AWGN channel. (No. of Users $=10, M=16$ )

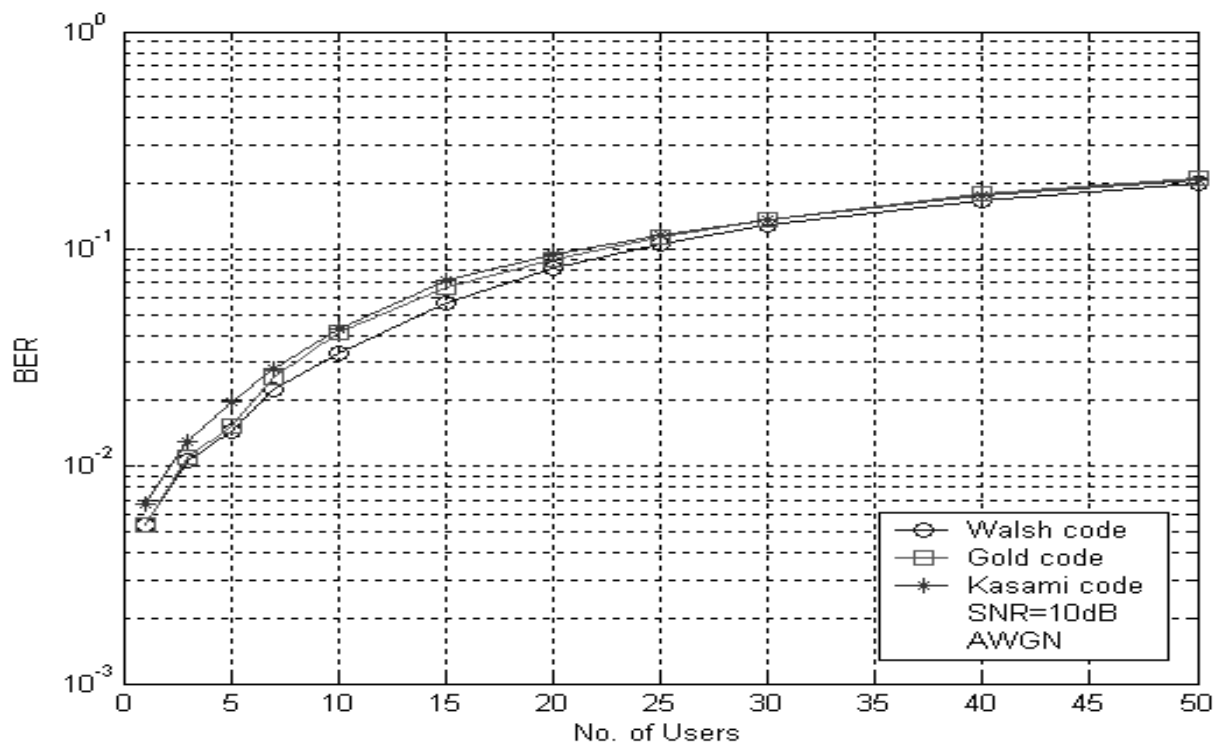

Figure 7. BER vs. No. of Users for MTC CDMA system using Walsh, Gold, and Kasami codes in AWGN channel. $(\mathrm{SNR}=10 \mathrm{~dB}, \mathrm{M}=16)$ 


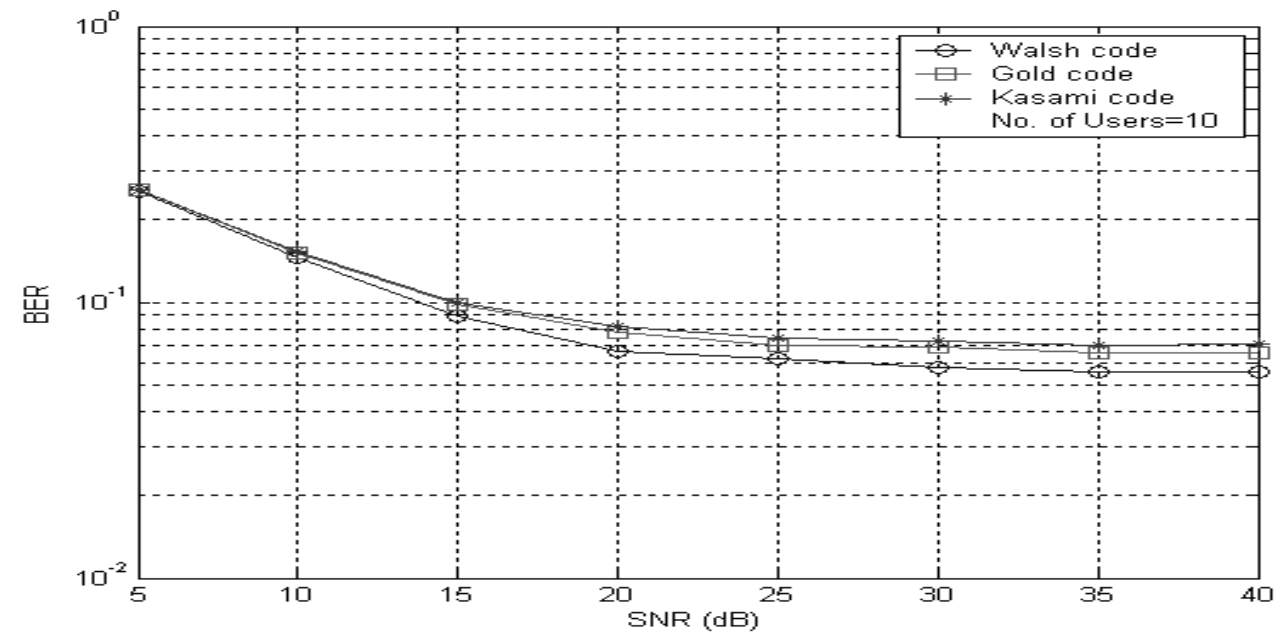

Figure 8. BER vs. SNR for MTC CDMA system using Walsh, Gold, and Kasami codes in Multipath fading channel. (No. of Users $=10, \mathrm{M}=16$ )

Fig. 9 shows the BER performance versus No. of users for the MTC CDMA system in AWGN and multipath fading channel. In fading channel, because of the effect of multipath fading, the system performance showed severe degradation. We increased the transmit power by $30 \mathrm{db}$ to achieve BER performance comparable to AWGN.

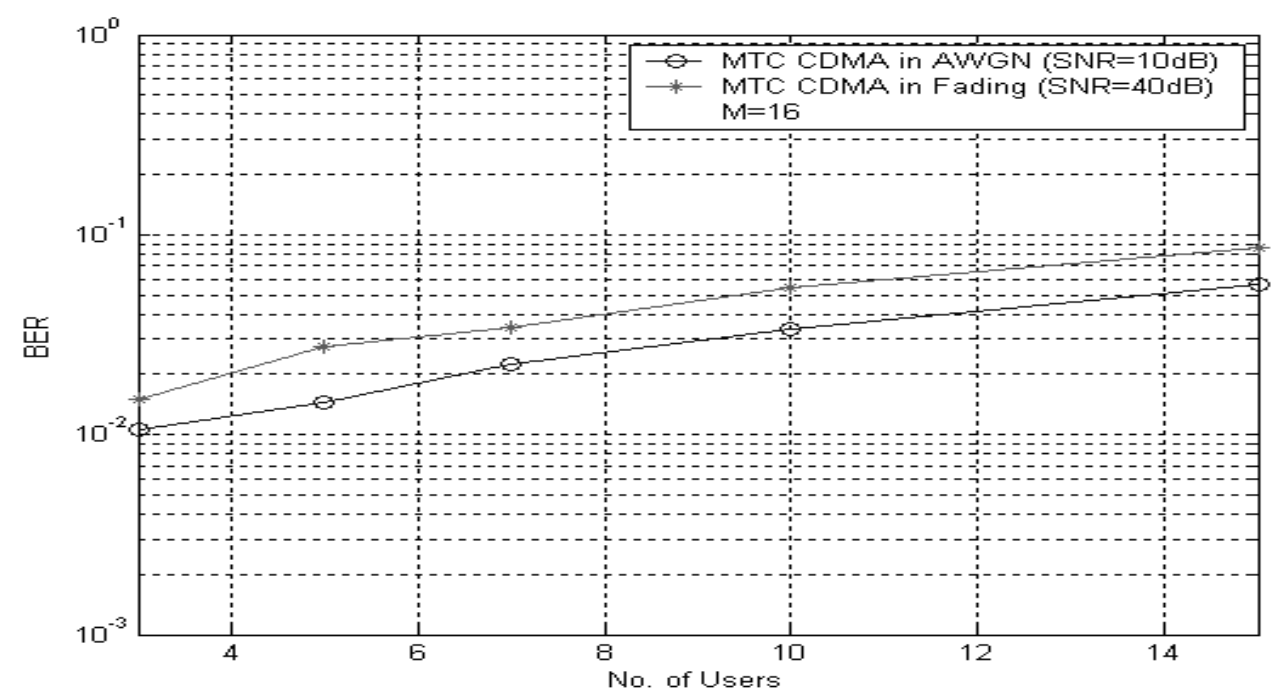

Figure 9. BER vs. No. of users for MTC CDMA system in AWGN (SNR=10dB) and in Fading $(\mathrm{SNR}=40 \mathrm{~dB})$ channel. $(\mathrm{M}=16)$

Fig.10 shows the comparison of the BER performance versus no. of users for MTC CDMA system with adaptation and without adaptation in multipath fading channel. The non-adaptive system uses 16-ary symbol. By using adaptation, we can increase the capacity without decreasing BER performance. For the BER of $10^{-2}$, we can increase the number of users from 3 to 8 with the adaptive algorithm compared to the system without the adaptation. Also, we can increase the effective data rate of the system using rate adaptation. This means the average $\mathrm{M}$ value for the system using the adaptation is greater than 16, which is the M used in non-adaptive system. 
Walsh code was chosen for multicode sequence sets for the MTC-MC system simulation, as it proved to be the best among the three codes used in MTC system in AWGN and fading channel. Fig. 11 shows the comparison of the BER performance for the MTC CDMA, MTC-MC CDMA without adaptation, and MTC-MC CDMA with adaptation in multipath fading channel.

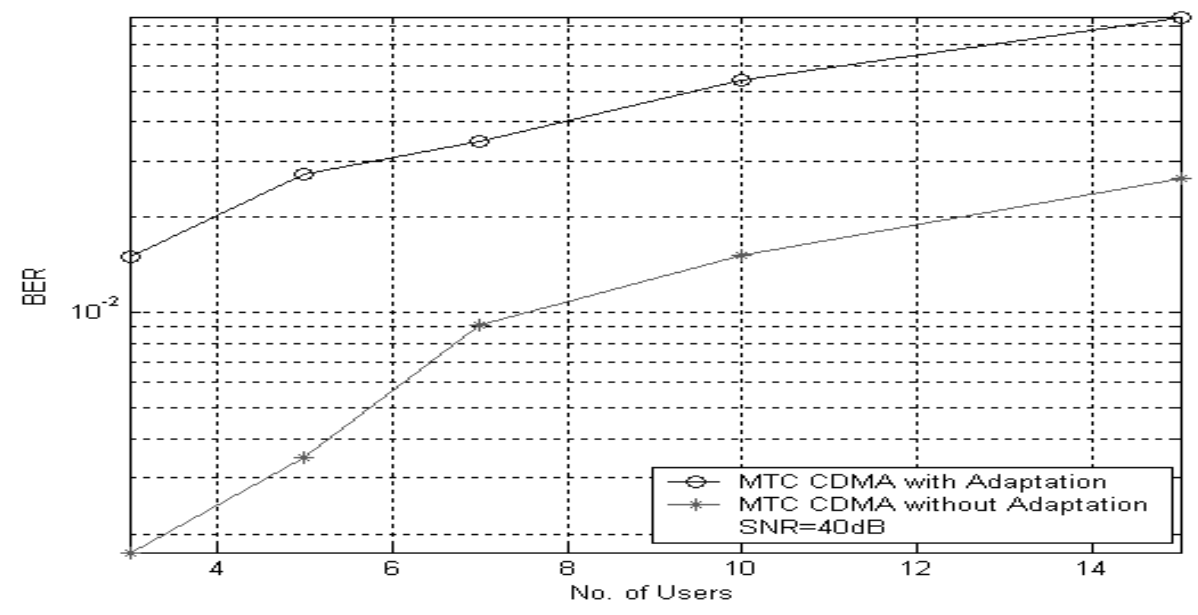

Figure 10. BER vs. No. of Users for MTC CDMA system with Adaptation and without Adaptation in Multipdath fading channel.(SNR $=40 \mathrm{~dB}, \mathrm{M}=16$ for MTC CDMA without Adaptation)

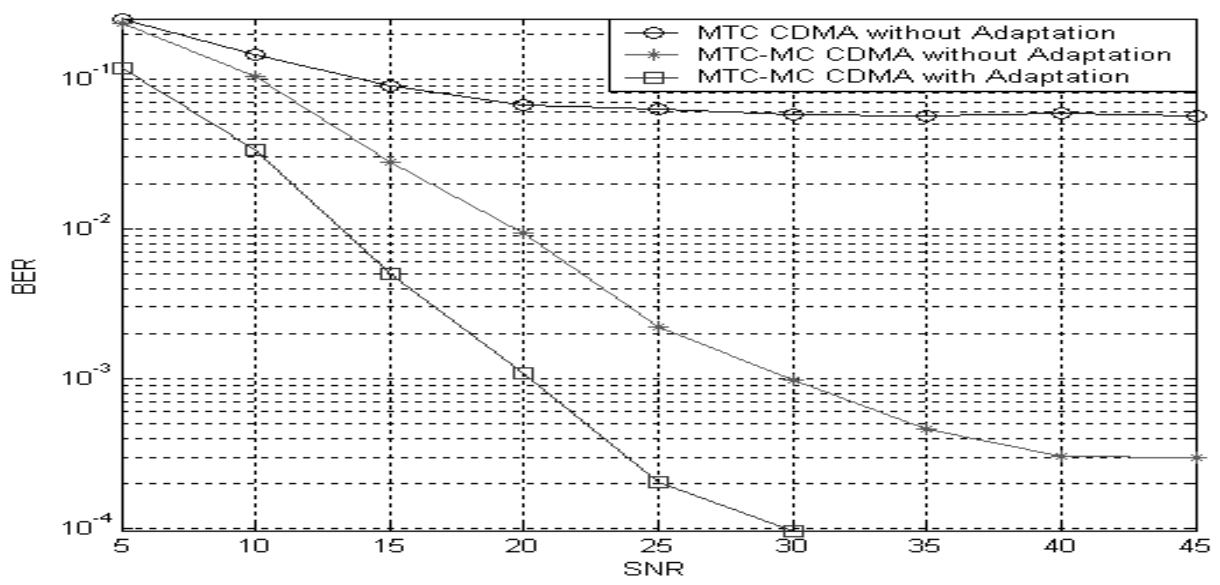

Figure 11. BER vs. SNR for MTC CDMA, MTC-MC CDMA without Adaptation, and MTCMC CDMA with Adaptation in Multipath fading channel. (No. of Users $=10$, Subcarrier $=16$ for MTC-MC, $\mathrm{M}=16$ for MTC CDMA and MTC-MC CDMA without Adaptation)

Our proposed MTC-MC CDMA system shows better BER performance than MTC CDMA system. MTC-MC CDMA system using adaptation outperforms other systems. For the BER of $10^{-3}$, about $5 \mathrm{~dB}$ gain in SNR is obtained by using the adaptive algorithm. As shown in Fig. 11, MTC CDMA system has poor BER performance in multipath fading channel; however, by using multi-carrier system with this multicode system, we can overcome the multipath fading effect as shown in Fig. 11. 
Fig. 12 shows the average M versus no. of users for MTC-MC CDMA system with adaptation. As the number of users increases, the BER performance can be maintained almost the same by decreasing the average $M$ value. Therefore, for a certain target BER, we can increase the capacity by controlling $\mathrm{M}$, the data rate, depending on the channel environment.

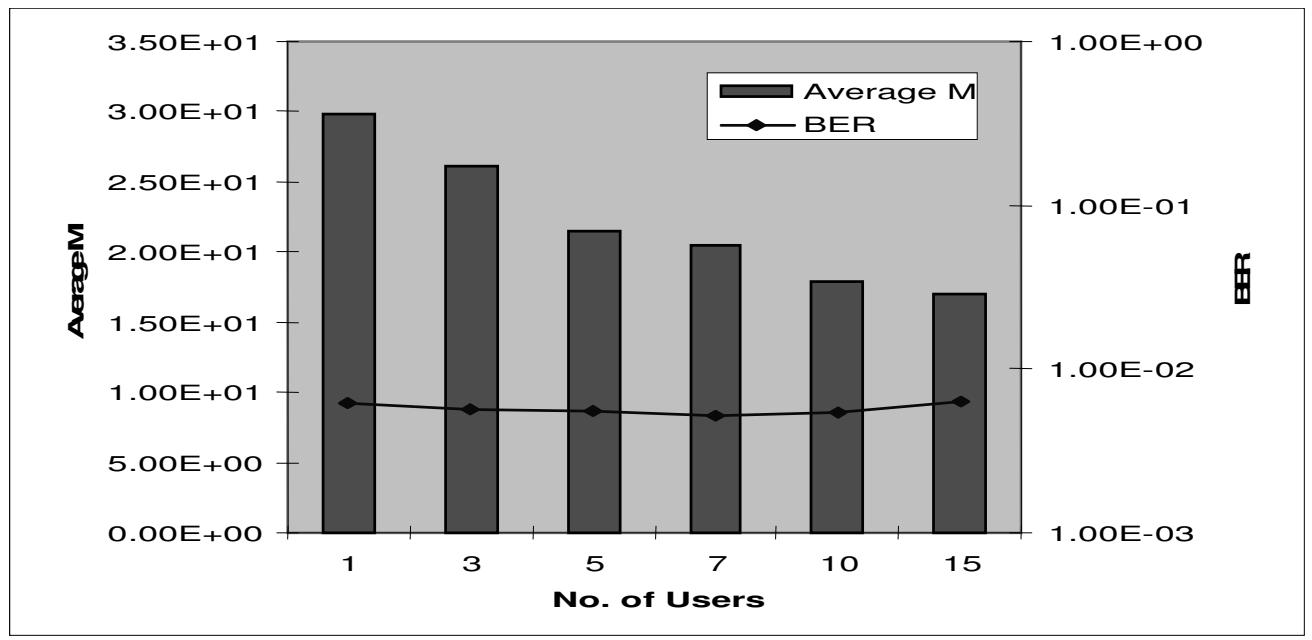

Figure 12. Average M versus No. of Users for MTC-MC CDMA with Adaptation in Multipath fading channel. $(\mathrm{SNR}=40 \mathrm{~dB})$

\section{Conclusion}

In this paper, we evaluate the performance of Multi-Code CDMA using different code sets in AWGN and in multipath fading channels. Compared to AWGN channel, the performance of the Multi-Code system degrades drastically in multipath fading channel. We propose a MultiCode Multi-Carrier CDMA system which retains the variable data rate capability of the MultiCode system and is robust to multipath fading like Multi-Carrier CDMA. The proposed system has significantly better BER performance to the original Multi-Code CDMA system and hence supports more users for the same BER in a fading channel. The rate adaptation algorithm proposed ensures that the average data rate traces the instantaneous channel condition and thereby improves the overall capacity of the system.

Further research will be aimed at determining the BER performance of the system in fading channel through mathematical analysis. The simulations for asynchronous data transmission in multipath fading channel using Multi-Code Multi-Carrier CDMA system will also be performed.

\section{REFERENCES}

[1] I, C.L., Gitlin, R.D., "Multi-Code CDMA Wireless Personal Communications Networks", Proceedings of IEEE International Conference on Communications, '95, Seattle, 1995, pp. 1060-1064.

[2] H.D. Schotten, H. Elders-Boll, and A. Busboom, "Adaptive Multi-Code CDMA Systems for Variable Data Rates", IEEE International Conference on Personal Wireless Communications ICPWC '97, Mumbai, 1997.

[3] Mitra, U., "Comparison of maximum-likelihood-based detection for two multi-rate access schemes for CDMA signals", IEEE Transactions on Comm., Vol 47, pp. 64-67, Jan 1999.

[4] Ottosson, T., Svensson, A., "Multi-rate schemes in DS/CDMA systems", Proc. IEEE Vehicular Technology Conference, pp. 1006-1010, 1995. 
International Journal of Computer Networks \& Communications (IJCNC) Vol.3, No.3, May 2011

[5] Cao, Y.W., Ko, C.C., Tjhung, T.T., A New Multi-code/Multi-carrier DS-CDMA System”, IEEE Global Telecommunications Conference, 2001. GLOBECOM '01. Volume:1, pp. 543 -546.

[6] Fu, P.W., Chen, K.C., "Multi-Rate MC DS-CDMA with Multi User Detections for Wireless Multimedia Communications", IEEE Vehicular Technology Conference, 2002. IEEE 55 $5^{\text {th }}$, Volume 3, pp. 1536-1540.

[7] U. Mitra, "Comparison of maximum-likelihood-based detection for two multi-rate access schemes for CDMA signals," IEEE Transactions on Communications, vol. 47, pp. 64-67, January 1999.

[8] 3GPP2, S. R0023, "High speed data enhancement for CDMA2000 1x-data only," June 2000.

[9] “Technical overview of 1xEV-DV," White paper, Motorola Inc., September 2002, version G1.4. [Online]. Available: http://www.cdg.org

[10] P. Bender, P. Black, M. Grob, R. Padovani, N. Sindhushayana, and A. Viterbi, "CDMA/HDR: a bandwidth-efficient highspeed wireless data service for nomadic users," IEEE Communications Magazine, vol. 38, pp. 70-77, July 2000.

[11] D. W. Hsiung and J. F. Chang, "Performance of multi-code CDMA in a multipath fading channel,” IEE Commun., vol. 147, pp. 365-370, December 2000.

[12] G. V. S. Raju and J. Charoensakwiroj, "Orthogonal codes performance in multi-code CDMA," 2003 IEEE Int. Conf. on Systems, Man and Cybernetics, vol. 2, pp. 1928-1931, October 2003.

[13] S. A. Khorbotly and O. C. Ugweje, "Diversity performance of multi-code spread spectrum CDMA system," IEEE WCNC, vol. 4, pp. 2087-2092, March 2004.

[14] D. Koulakiotis and A. H. Aghvami, "Performance enhancement of multi-code CDMA using interference cancellation," IEEE 5th Int. Symp. on Spread Spectrum Techniques and Applications, Sun City, vol. 1, pp. 130-134, September 1998.

[15] M. Saito and H. Yamamoto, "Sequence assignment ofWalsh-Hadamard sequences for quasisynchronous multi-code CDMA systems," 2002 5th Int. Symp. On Wireless Personal Multimedia Commun., vol. 2, pp. 673-677, October 2002.

[16] J. Choi, "Channel estimation for coherent multi-carrier CDMA systems over fast fading channels," IEEE 51st 2000 Spring Conf. on Vehicular Technology, Tokyo Japan, vol. 1, pp. 400404, May 2000.

[17] K. W. Ryu, J. O. Park and Y. W. Park, "Performance of multicarrier CS/CDMA in frequencyselective Rayleigh fading channels," 2003 Spring IEEE $57^{\text {th }}$ Semiannual Vehicular Technology Conf., vol. 2, pp. 1258-1262, April 2003.

[18] S. A. Matin, Performance of Multitone CDMA Communication System with Diversity, Narrowband Signaling and Coding, Masters Degree Thesis, The University of Akron, May 2001.

[19] S. A. Khorbotly, Performance Analysis of Multi-code Spread Spectrum CDMAModulation, Maters Degree Thesis, The University of Akron, May 2003.

[20] S. J. Lee, S. Y. Hwang and J. S. Kim, "Low-complexity architecture of rake receiver for multicode CDMA system,” Electronics Letters, vol. 34, pp. 1382-1383 July 1998.

[21] Y. H. Chung and S. I. Jeong, "Improvements of performance and capacity in DS-CDMA with carrier interference over flat and frequency selective fading channels," IEEE 2002 Spring 55th Conf. on Vehicular Technology, vol. 3, pp.1434-1437, May 2002.

[22] V. Ramanathan and A. Annamalai, "Analysis of equal gain diversity receivers in correlated Rayleigh fading channels,” IEEE Commun. Letters, vol. 8, pp. 362-364, June 2004.

[23] Y. Chen and C. Tellambura, "Performance analysis of L-branch equal gain combiners in equally correlated Rayleigh fading channels," IEEE Commun. Letters, vol. 8, pp. 150-152, March 2004. 
International Journal of Computer Networks \& Communications (IJCNC) Vol.3, No.3, May 2011

[24] H. K. Park, E. B. Kim, Y. W. Lee and K. H. Tchah, "Multi-carrier CDMA system with parallel interference cancellation for multipath fading channels," IEEE 19989th Int. Symp. on Personal, Indoor and Mobile Radio Communications, Boston, MA, vol. 2, pp. 513-517, September 1998.

[25] D. N. Rowitch and L. B. Milstein, "Convolutionally coded multicarrier DS-CDMA systems in a multipath fading channel-Part I: performance analysis," IEEE Trans.Commun., vol. 47, no. 10, pp. 1570-1582, October 1999.

[26] M. Tan and Y. Bar-Ness, "Performance comparison of the multi-code fixedspreading length scheme and the variable spreading length scheme for multi-rate MC-CDMA," 2002 IEEE 7th International Symp. on Spread Spectrum Techniques and Applications, vol. 1, pp. 108-112, 2002.

[27] K. S. Lim and J. H. Lee, "Performance of Multirate Transmission Schemes for a Multicarrier DS/CDMA System," IEEE 2001 Fall 54th Conf. on Vehicular Technology, Atlantic City, NJ, vol. 2, pp. 767-771, October 2001.

[28] Taeyoon Kim, Jaeweon Kim, Jeffrey G. Andrews, and Theodore S. Rappaport, "Multi-code Multi-Carrier CDMA: Performance Analysis,” IEEE Int. Conf., vol. 2, pp. 973-977, Ju

[29] Rappaport, T. S., Wireless Communications, Principles and Practice, $2^{\text {nd }}$ ed., Prentice Hall PTR, 2002.

[30] Smith, J. I., “A Computer Generated Multipath Fading Simulation for Mobile Radio," IEEE Tr. on Vehicular Technology, Vol. VT-24, No.3, pp. 39-40, Aug. 1975.

[31] Stuber, G. L., Principles of Mobile Communication, Kluwer Academic Publishers, Massachusetts, 1996.

\section{Biography}

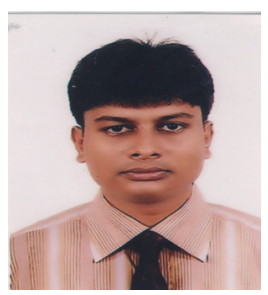

Md. Sadek Ali received the Bachelor's and Master's Degree in the Department of Information and Communication Engineering (ICE) from Islamic University, Kushtia, in 2004 and 2005 respectively. He is currently a Lecturer in the department of ICE, Islamic University, Kushtia-Bangladesh. Since 2003, he has been working as a Research Scientist at the Communication Research Laboratory, Department of ICE, Islamic University, Kushtia, where he belongs to the spread-spectrum research group. He has three published paper in international and one national journal in the same areas. His areas of interest include Wireless Communications, optical fiber communication, Spread Spectrum and mobile communication.

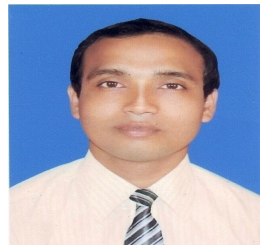

Md. Shariful Islam received the Bachelor's and Master's Degree in Applied Physics, Electronics \& Communication Engineering from Islamic University, Kushtia, Bangladesh in 1999, and 2000 respectively. He is currently Assistant Professor in the department of ICE, Islamic University, Kushtia-7003 Bangladesh. $\mathrm{He}$ has five published papers in international and national journals. His areas of interest include signal processing \& mobile communication.

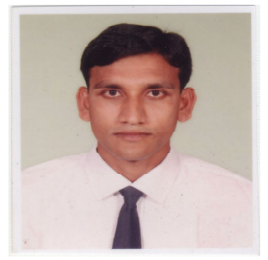

Md. Alamgir Hossain received the Bachelor's and Master's Degree in the Dept. of Information and Communication Engineering (ICE) from Islamic University, Kushtia, in 2003 and 2004, respectively. He is currently Lecturer in the department of ICE, Islamic University, Kushtia-7003, and Bangladesh. He was a lecturer in the Dept. of Computer Science \& Engineering from Institute of Science Trade \& Technology (Under National University), Dhaka, Bangladesh. from 23th October, 2007 to $18^{\text {th }}$ April 2010. Since 2003, he has been working as a Research Scientist at the Communication Reasearch Laboratory, Department of ICE, Islamic University, Kushtia, where he belongs to the spread-spectrum research group. His current research interests include Wireless Communications, Spread Spectrum and mobile communication, Signal processing, Data Ming. 
International Journal of Computer Networks \& Communications (IJCNC) Vol.3, No.3, May 2011

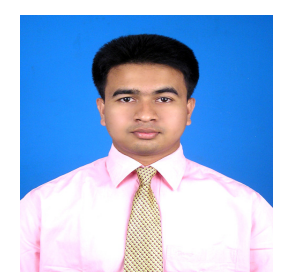

Md. Khalid Hossain Jewel obtained his Bachelor's, and Master's degree from the dept. of Applied Physics, Electronics \& Communication Engineering of Islamic University, Kushtia-7003, Bangladesh in 2004 and 2005 respectively. Now he is currently a lecturer in the department Applied Physics, Electronics \& Communication Engineering of Islamic University, Kushtia-7003 Bangladesh. Beside this he is an M.Phil research fellow in the field of mobile communication. $\mathrm{He}$ published one research paper in an international journal in the same field. His research interest is cellular mobile communication, Ad-hoc wireless communication and optical fiber communication. 